\title{
Online pharmacy still open despite counterfeit allegations
}

— Cite as: CMAJ 2017 August 8;189:E1023-4. doi: 10.1503/cmaj.1095461

Posted on cmajnews.com on July 17, 2017.

$\mathbf{T}$ he founder of CanadaDrugs.com and five others associated with the online pharmacy are wanted for prosecution in the United States for selling unapproved and counterfeit medicines to American doctors, but a decision on their extradition may be months away.

CanadaDrugs' president and founder, Kristjan Thorkelson, is set to appear in Manitoba's top court for a pretrial conference on Aug. 22. Joining him will be Ronald Sigurdson (chief financial officer), Darren Chalus (director of clinical sales), Troy Nakamura (clinical manager) and Thomas Haughton (president of two CanadaDrugs' subsidiaries). British Columbia's Supreme Court has adjourned the case of a sixth man, James Trueman, until early September.

Once hearings are scheduled, "it could take several weeks or even months" before the courts decide whether there is sufficient evidence to extradite the men, said Ian McLeod, media relations adviser with the Department of Justice. "The time it takes to complete an extradition hearing depends on a number of factors, including whether the hearing will be contested."

Lawyers for the men declined to comment, but Joe Weinstein, who is representing Chalus, stated "we will be fighting the request for extradition."

In the meantime, CanadaDrugs remains open for business and licensed by both Health Canada and the College of Pharmacists of Manitoba. In a statement, the college said it is watching the court proceedings "carefully," but claimed that "pharmacies licensed by the college are safe."

Health Canada suspended CanadaDrugs' license to sell wholesale prescription drugs in 2014, citing "significant concerns" with manufacturing processes.

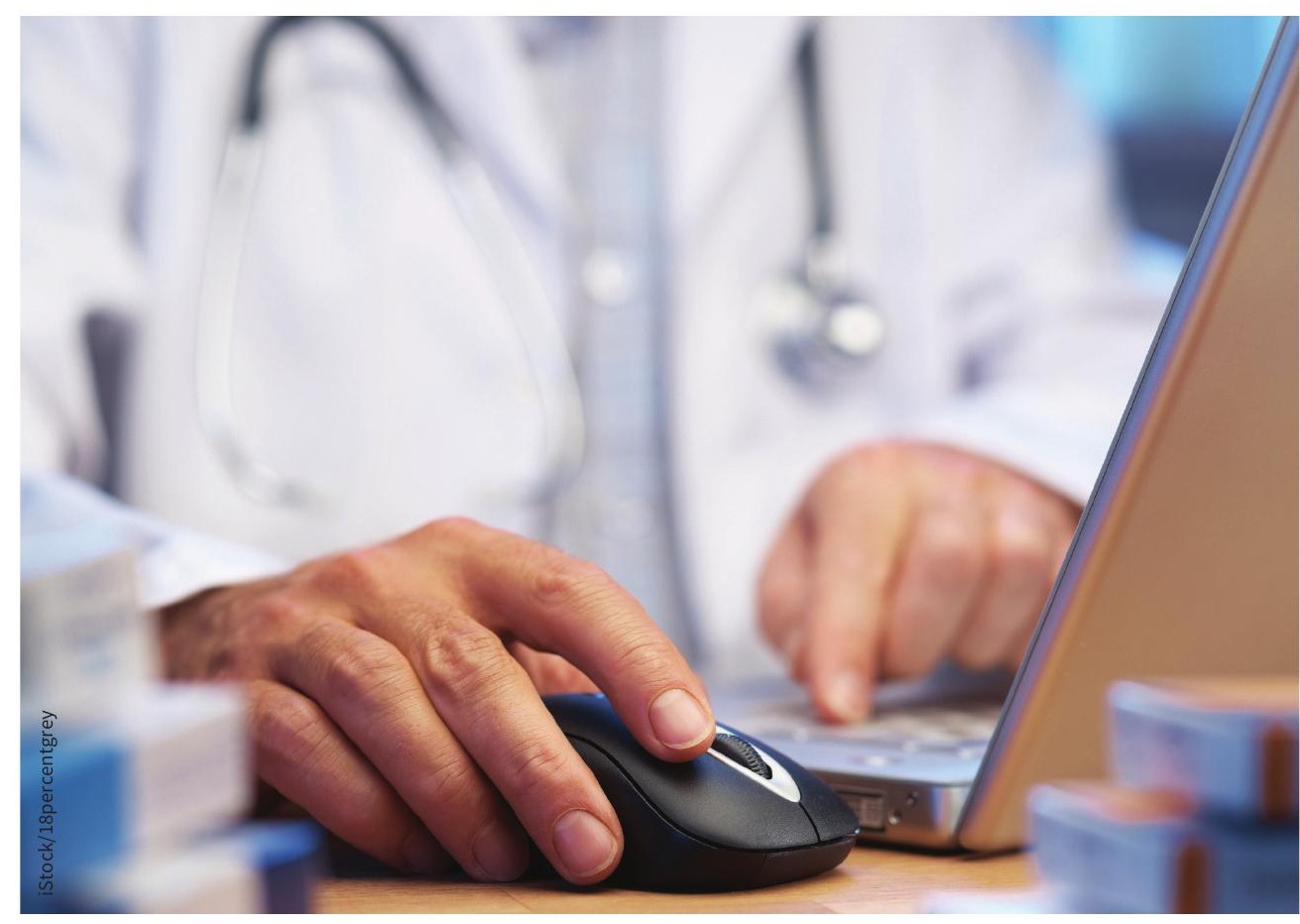

CanadaDrugs.com remains open for business as its executives face a potentially lengthy extradition battle.

However, that license was reinstated in 2016 following an inspection.

Both Health Canada and Manitoba's college of pharmacists have tended to turn a blind eye to violations of Canadian and American laws by Internet pharmacies, said Amir Attaran, a professor of law and medicine at the University of Ottawa. "Health Canada has refused for years to prosecute any criminal Internet pharmacies," he said. Meanwhile, the college continues to collect fees and license them. For this, "its officials could - and I strongly believe should - be indicted for conspiracy in the US."

SafeMedicines.org reports that CanadaDrug previously boasted on its website of selling imported drugs to Americans since 2001. Now, the company's terms of sale state that "virtually all shipments of prescription drugs imported from an international pharmacy by a United States customer will violate United States law."

The US Food and Drugs Administration began investigating the company in 2012 after it sold at least one American physician fake cancer drugs containing no active ingredients, according to a 2014 indictment.

Prosecutors allege CanadaDrugs illegally imported and sold US\$78 million in unapproved, mislabeled, contaminated or counterfeit medicines to Americans. They also accuse the company of falsifying customs declarations and improperly storing drugs. 
In emails provided to Manitoba's top court and authenticated by Microsoft, Trueman was notified that a physician returned two units of Dysport (a form of botulinum toxin A that blocks nerve activity in muscles) because the cold packs shipped with the product were warm. He responded, "Just put in freezer they will be ok."
US investigators also taped a conversation in which a CanadaDrugs affiliate told a cancer clinic employee that "the drugs we sold were never FDA approved ... That is why you are able to get the prices you are getting."

Thorkelson and his associates are charged with smuggling, conspiracy and international money laundering. If con- victed, they could face 20 years in prison and fines.

Two Americans have already pleaded guilty in the case and are expected to testify at the US trial, along with a third man whose charges were dropped in exchange for his testimony.

Lauren Vogel, CMAJ 